\title{
El activismo judicial en el proceso disciplinario*
}

\author{
Ximena Patricia Bahamón Pedroza** \\ Yasmín Zoraida Gómez***
}

Recibido: 15 de noviembre de 2016 • Aprobado: 30 de marzo de 2017

\section{Resumen}

El presente artículo de investigación expone un análisis crítico fundamentado en lo expuesto por la jurisprudencia constitucional en consonancia con la descripción de la naturaleza jurídica del derecho disciplinario como rama independiente del derecho, generándose la pregunta problema así planteada: ¿Cómo opera el activismo judicial en el procedimiento disciplinario? En tal sentido, la investigación plantea 3 objetivos, a saber: 1) establecer la naturaleza del activismo judicial en el proceso disciplinario; 2) descubrir cuáles son las causales del activismo judicial en el proceso disciplinario determinado en la Ley 734 de 2002; 3) determinar la forma de consolidar el derecho al debido proceso dentro del derecho disciplinario garante. $Y$ así, luego de la valoración mencionada, se determinó lo que día tras día sucede en la esfera del derecho disciplinario en los procesos seguidos en contra de funcionarios públicos o de particulares que ejercen funciones públicas con el fin de establecer la forma en que opera el activismo judicial, en lo que respecta a la calificación de las faltas y a la imposición de sanciones. Así, en la actualidad nacional se evidencia la necesidad de elaborar e implementar una nueva normativa disciplinaria que

"Artículo resultado de la investigación titulada El activismo judicial en el proceso disciplinario, para optar al título de especialista en Derecho Administrativo de la Universidad Santo Tomás. Bogotá, Colombia. DOI: http://dx.doi.org/10.15332/s1900-0448.2017.0047.06

*" Abogada y Especialista en Derecho Administrativo de la Universidad Santo Tomás. Bogotá, Colombia. Especialista en Derecho Laboral de la Universidad Externado de Colombia. Bogotá, Colombia. Correo electrónico: ximena.bahamon@prosperidadsocial.gov.co

**a Abogada de la Universidad Católica de Colombia. Bogotá, Colombia. Especialista en Derecho Administrativo de la Universidad Santo Tomás. Bogotá, Colombia. Correo electrónico: yzgomez1@ gmail.com 
contenga en todo el articulado el principio de legalidad que prevalece en todo el ordenamiento jurídico interno, en especial en la aplicación del ius punendi estatal.

Palabras clave: activismo judicial, derecho disciplinario, tipos en blanco, principio de legalidad.

\title{
Judicial Activism in the Disciplinary Process
}

\begin{abstract}
The present research article exposes a critical analysis based on the foregoing by the constitutional courts in accordance with the description of the legal nature of the disciplinary law as independent branch of law, generating the question problem thus raised: How operates the judicial activism in the disciplinary procedure? In this regard, the research raises 3 objectives namely: 1) establish the nature of judicial activism in the disciplinary process; 2) find out what are the grounds for judicial activism in the particular disciplinary process in the Act 734 of 2002;3) determine how to strengthen the right to due process within the secured disciplinary law. And so, after the aforementioned valuation could be determined what happens day after day in the field of disciplinary law in the processes followed against public officials or private individuals who exercise public functions in order to establish how it works the judicial activism with respect to the qualification of the faults and the imposition of sanctions. Thus, currently national is evidence the need of develop and implement a new regulatory disciplinary that contains in all the articulated the principle of legality that prevails in all the ordering legal internal especially in application of the ius punendi state.
\end{abstract}

Keywords: Citizen Security, Public Order, Security Forces, Surveillance, Authorization of Video Surveillance Systems, Video Surveillance Law.

\section{O ATIVISMO JUDICIAL NO PROCESSO DISCIPLINAR}

\section{Resumo}

Este artigo de pesquisa apresenta uma análise crítica fundamentada no exposto pela jurisprudência constitucional no relacionado com a descrição da natureza jurídica do direito disciplinar como área independente do direito, gerando-se a pergunta: como opera o ativismo judicial no procedimento disciplinar? Neste sentido, a 
pesquisa expõe três objetivos 1) estabelecer a natureza do ativismo judicial no processo disciplinar; 2) descobrir quais são as causas do ativismo judicial no processo disciplinar determinado na (Lei 734 de 2002;3) determinar a forma de consolidar o direito ao devido processo dentro do direito disciplinar garante. Assim, depois da valoração mencionada, se determinou o que acontece dia a dia no âmbito do direito disciplinar nos processos em contra de funcionários públicos ou particulares que exercem funções públicas com o objetivo de estabelecer a forma na qual opera o ativismo judicial, no relacionado com a qualificação das faltas e a imposição de sanções. Assim, na atualidade nacional se evidencia a necessidade de elaborar e implementar uma nova normativa disciplinar que contenha em todos os artigos o princípio de legalidade que prevalece em todo ordenamento jurídico interno, em especial na aplicação do ius punendi estatal.

Palavras-chave: ativismo judicial, direito disciplinar, tipos em branco, princípio de legalidade.

\section{Introducción}

Atendiendo lo dispuesto por Blanco, "el fenómeno de la globalización ha generado un cambio de organización política y jurídica en la figura del Estado Nación sin que dicha modificación presente elementos institucionales que garanticen una transición pacífica, equilibrada, legítima y justa" (2010). Desde la citada perspectiva, en el ámbito del derecho público, uno de los hechos trascendentales es el enorme desarrollo que ha tenido el derecho disciplinario, al punto en que se puede hablar de un derecho sancionador autónomo e independiente con características y fundamentos propios que la distinguen del derecho administrativo y del derecho penal; evolución que se debe a los pronunciamientos de las altas cortes, a las decisiones de la Procuraduría General de la Nación y a todos aquellos aportes que desde la doctrina se han realizado.

En el marco de la temática que se pretende abordar en estas páginas, es importante aclarar como antecedente al problema de investigación planteado, lo dispuesto por el profesor Forero (2016), quien ha considerado que:

En Colombia ha surgido un derecho disciplinario con bastante margen de autonomía respecto del derecho penal y el derecho administrativo sancionador, que entra a conciliar la tensión constitucional que a diario se observa en la dinámica 
de su administración pública, generada de una parte, por la obligación de la administración, de materializar la moralidad, efectividad, eficacia y eficiencia, y, de otro lado, el imperativo propio, por garantizar y proteger los derechos fundamentales de los servidores estatales, esto es, servidores públicos y particulares en ejercicio de funciones públicas (p. 89).

Así pues, y de conformidad con Berdugo (2013), la doctrina y la jurisprudencia coinciden, en primer lugar, en que el fundamento del derecho disciplinario es la infracción del deber funcional, cuyo vínculo de obligatoriedad tiene su explicación en una categoría especial denominada relación especial de sujeción. En segundo lugar, el derecho disciplinario se caracteriza por ser un régimen de responsabilidad subjetiva distinto a los regímenes sancionadores de responsabilidad objetiva. Y en tercer lugar, en materia de tipicidad, la mayoría de faltas están contenidas en tipos abiertos; en cuanto a la antijuridicidad, el derecho disciplinario tiene una categoría propia que es el eje más importante y que corresponde al fundamento de lo injusto o ilícito: la ilicitud sustancial; en materia de culpabilidad y a pesar de que se mantienen los mismos títulos de imputación subjetiva que en el derecho penal el dolo y la culpa descansan sobre los conceptos de previsión efectiva y diligencia exigible, premisas sobre las cuales se puede concluir que el servidor público tiene un mayor grado de exigibilidad que el de cualquier persona (Berdugo et al., 2013).

En suma, una de las cuestiones más importantes por resolver por parte del derecho disciplinario, es la problemática propuesta mediante la siguiente pregunta de investigación: ¿Cómo se materializa el activismo judicial en el marco del proceso disciplinario determinado en la Ley 734 de 2002?, problemática que se desarrolla con fundamento en la naturaleza jurídica de esta rama del derecho y las particularidades propias del principio de legalidad inmersas de manera sustancialmente diferente en el derecho disciplinario.

En este orden de ideas, se realiza una investigación cualitativa en la que se recolectan datos no estandarizados ni completamente predeterminados, es decir, sin medición numérica, con lo cual se llegará a delimitar los subtemas de investigación. Por lo anterior, a través del método dogmático de investigación que pretende explicar el orden jurídico tal como es y completándolo también, en este caso a través de la elucubración de la naturaleza jurídica del activismo judicial para luego evaluar la forma en que opera dentro del derecho disciplinario, con el ánimo de plantear soluciones alternativas en procura de dotar el procedimiento disciplinario de reales 
garantías constitucionales y de un respeto efectivo por los derechos fundamentales de los sujetos disciplinados.

En este sentido, el presente texto muestra los resultados de una investigación socio-jurídica y exploratoria encaminada a puntualizar las causales que explican el desarrollo y la posible transformación del derecho disciplinario.

\section{Naturaleza del activismo judicial en el proceso disciplinario}

Green (2009, p. 1208) sostiene que han existido cuatro posturas respecto del fenómeno del activismo judicial, entendido entonces como: 1) un error judicial grave; 2) un resultado controversial o indeseable; 3) cualquier decisión que anule una ley; 4) una combinación de las anteriores con otros factores. Concluyendo el autor que la postura más aceptable apunta a combinar los elementos mencionados con otros factores.

A su vez, Green propone definir el activismo judicial como aquel abuso de poder sin supervisión ${ }^{1}$, permitiendo ello pensar que se ejerce fuera de los límites de la función judicial; coincidiendo dicha definición con la propuesta por Cabrillo (2011) que reza así:

(...) el activismo se presenta cuando existen decisiones de los órganos de la administración de justicia que van más allá de la estricta aplicación de la ley, para extender algunos de sus principios a situaciones nunca previstas por el legislador; $\mathrm{y}$ ante las que cabe, además, pensar razonablemente que el legislador no habría actuado en tal dirección en el momento de promulgar la norma (p. 2).

El derecho disciplinario se ha erigido como rama autónoma e independiente, buscando regular las relaciones del Estado con sus funcionarios y con los particulares que le colaboran en la consecución de sus fines, es decir, dichas funciones se desarrollan dentro del marco de las relaciones de sujeción especial en las cuales los individuos tienen unas cargas superiores a las del común de las personas (Ramírez y Álvarez, 2015, p. 346).

\footnotetext{
${ }^{1}$ Cuando el autor habla de "poder sin supervisión" lo hace refiriéndose a la fortaleza que tienen las decisiones judiciales y la independencia que tiene la judicatura, como el carácter vitalicio del cargo y la inexistencia de juicio político para los jueces en el sistema norteamericano.
} 
En este orden de ideas, la potestad disciplinaria se encuentra regida por los principios que regulan el poder sancionatorio estatal, lo cual supone la estricta aplicación de los cimientos que regulan el derecho sancionador, tales como el principio de legalidad, tipicidad, antijuridicidad, con los matices impuestos por su naturaleza.

Así lo ha entendido la Corte Constitucional al manifestar que siendo el derecho disciplinario una de las manifestaciones del ius puniendi, el ejercicio del poder sancionador del Estado exige la garantía del debido proceso en tales actuaciones administrativas como lo ordena el artículo 29 superior, esto quiere decir que aun cuando el derecho sancionador administrativo comparte con el derecho penal un conjunto de elementos, no es menos cierto que existen ciertas diferencias en razón de su especificidad, pues tanto el derecho administrativo sancionador como el derecho penal son manifestaciones de la potestad punitiva estatal; siendo el primero un derecho autónomo con finalidades propias tales como el óptimo funcionamiento de las ramas y órganos del Estado y el correcto desempeño de los titulares de la función pública sentencia (Corte Constitucional, 2010).

El derecho disciplinario como forma de ejercicio de la potestad sancionadora del Estado, debe estar fundado en principios y valores constitucionales y debe asegurar la vigencia de los elementos propios de la garantía del debido proceso: 1) principio de legalidad de la falta y de la sanción disciplinaria; 2) principio de publicidad;3) derecho de defensa y especialmente el derecho de contradicción y de controversia de la prueba; 4) principio de la doble instancia; 5) presunción de inocencia; 6) principio de imparcialidad; 7) principio de non bis in idem; 8) principio de cosa juzgada; 9) prohibición de la reformatio in pejus. Todos estos principios consagrados a nivel internacional en múltiples instrumentos incluidos en la legislación interna a través del Bloque de Constitucionalidad.

Es pertinente aclarar que el Bloque de Constitucionalidad es aquella unidad jurídica compuesta, según la Corte Constitucional (2003):

Por normas y principios que, sin aparecer formalmente en el articulado del texto constitucional, son utilizados como parámetros del control de constitucionalidad de las leyes, por cuanto han sido normativamente integrados a la Constitución, por diversas vías y por mandato de la propia Constitución. Son pues verdaderos principios y reglas de valor constitucional, esto es, son normas situadas en el nivel constitucional, a pesar de que puedan a veces contener mecanismos de reforma diversos al de las normas del articulado constitucional strictu sensu (Sentencia C-067/03). 
Dichos estándares internacionales serán analizados a partir de los fallos de la Procuraduría General de la Nación emitidos entre 2010 y 2014, en los que ha sancionado con la destitución a servidores públicos de elección popular, en especial los emitidos dentro de los procesos disciplinarios identificados así: radicados UIS 2012-447489 del 9 de diciembre de 2013 en contra del entonces alcalde mayor de Bogotá, Gustavo Francisco Petro Urrego; IUS 2011-381575 del 29 de febrero de 2012 en contra del exalcalde de la ciudad de Medellín, Alfonso Salazar Jaramillo; y el UIS 2008-305318 emitido el 27 de septiembre de 2010 en contra de la exsenadora de la República Piedad Esneda Córdoba Ruiz, fundamentados en el contenido del artículo 277 de la Constitución Política de Colombia.

Ahora bien, en el denominado bloque de constitucionalidad entre otros instrumentos encontramos la Declaración universal de los derechos bumanos, el Pacto internacional de derechos civiles y politicos y por supuesto la Convención americana sobres derechos humanos, pacto de San José de Costa Rica, ratificado por el Congreso de Colombia mediante la Ley 16 del 30 de diciembre de 1972, que en su artículo 23 estipula que los derechos políticos solo pueden ser limitados exclusivamente por razones de edad, nacionalidad, residencia, idioma, instrucción, capacidad civil o mental, o condena, por juez competente en un proceso penal; sin embargo, en Colombia, vale la pena preguntarse si la Procuraduría General de la Nación bajo las potestades constitucionales y legales como organismo de carácter administrativo respeta los estándares internacionales cuando sanciona funcionarios públicos de elección popular.

Cuestionamiento que puede responderse en el análisis elaborado por la Corte Constitucional en sentencia C-500 de 2014 cuando se refiere a la posición preferente que tiene el poder disciplinario atribuido al procurador y que solamente es desplazado por la existencia de fueros especiales o por la competencia asignada a la comisión del gobierno judicial. Es, además, constitucionalmente posible que en desarrollo de lo dispuesto en el artículo 26 de la carta y en ejercicio del margen de configuración que en esta materia le confiere la Constitución, el legislador establezca la destitución como una sanción disciplinaria atribuyendo su imposición al procurador general de la nación por sí o por medio de sus delegados o agentes.

En dicha oportunidad, la corte concluyó que no se violaban el artículo 25 de la Convención americana de derechos humanos y el artículo 93 de la Constitución, pues en atención a la naturaleza jurídica de las decisiones de las autoridades disciplinarias y a la existencia de medios judiciales suficientes para impugnarlas y por 
esa vía solicitar el amparo de los derechos a ser elegido y a acceder al ejercicio de funciones públicas, la norma examinada no se oponía al deber de asegurar un recurso judicial efectivo para la protección de los derechos. En efecto, el ordenamiento jurídico colombiano consagra la posibilidad de ejercer acciones judiciales ante la jurisdicción contencioso-administrativa para controvertir las decisiones adoptadas en instancias disciplinarias y, en casos excepcionales, es posible acudir también a la acción de tutela para controvertir dichas decisiones (Corte Constitucional, 2014).

Sobre el particular, en sentencia del 1 de septiembre de 2011 sobre el caso de Leopoldo López vs. Venezuela, la Corte Interamericana sostuvo que la restricción de su derecho al sufragio pasivo (ser elegido) ha debido imponerse en virtud de una condena, por juez competente, en proceso penal, en el que tendrían que haberse respetado las garantías judiciales consagradas en el artículo 8 de la Convención, lo cual no había ocurrido en su caso:

107. El artículo 23.2 de la Convención determina cuáles son las causales que permiten restringir los derechos reconocidos en el artículo 23.1, así como, en su caso, los requisitos que deben cumplirse para que proceda tal restricción. En el presente caso, que se refiere a una restricción impuesta por via de sanción, debería tratarse de una "condena, por juez competente, en proceso penal". Ninguno de esos requisitos se ha cumplido, pues el órgano que impuso dichas sanciones no era un "juez competente", no bubo "condena" y las sanciones no se aplicaron como resultado de un "proceso penal", en el que tendrían que haberse respetado las garantías judiciales consagradas en el artículo 8 de la Convención americana (Corte Interamericana de Derechos Humanos, 2011).

Sin embargo, ese propio tribunal recordó que todos los órganos que ejerzan funciones de naturaleza materialmente jurisdiccional, sean penales o no, tienen el deber de adoptar decisiones conforme a las garantías del debido proceso. Y a continuación reconoció expresamente que "las sanciones administrativas y disciplinarias son, como las penales, una expresión del poder punitivo del Estado y que tienen, en ocasiones, naturaleza similar a la de estas" (Corte Interamericana de Derechos Humanos, 2001, párr. 106; 23 de noviembre de 2010, párr. 170), de manera que lo que se exige es que en el marco de esas actuaciones se respeten el debido proceso y las garantías que le son inherentes.

De otra parte, la Corte Interamericana (2011) sostuvo que, dados los alcances de la restricción al sufragio pasivo implicados en una inhabilitación para ser 
candidato, el contralor tenía un deber de motivación explícita de la decisión, tanto en lo cualitativo como en lo cuantitativo, lo cual no había ocurrido en los actos sancionatorios de inhabilitación; y constató que los recursos judiciales interpuestos por el señor López Mendoza no cumplieron con dar una respuesta efectiva e idónea para proteger su derecho a ser elegido (...) y que pudiera salvaguardar las exigencias mínimas del deber de motivación en los procesos que derivaron en sanciones de inhabilitación (...).

Así las cosas, bien podría señalarse que la figura del activismo judicial en $\mathrm{Co}^{-}$ lombia en materia disciplinaria, he encontrado unas mínimas manifestaciones, entre ellas, la potestad que erige al Procurador General de la Nación de conocer, instruir y fallar en procesos de única instancia a funcionarios elegidos por elección popular, violando de igual forma el artículo 29 de la Constitución Nacional al no establecer para estos casos una segunda instancia autónoma e independe al censor de primera, correspondiendo por ende, a que el sujeto disciplinable en aras de buscar una independencia y objetividad en la decisión de acudir a la jurisdicción contenciosa administrativa, lo hiciera a través de la utilización de principios mutatis mutandi como el de proporcionalidad, razonabilidad y racionalidad, o en casos de violación flagrante instaurar acción de tutela.

Otro aspecto relevante en el cual se podría darse visos del activismo judicial en materia disciplinaria corresponde a la discrecionalidad que otorga la Ley 734 de 2002, concordante con la 1474 de 2011, al momento de graduar la sanción del inculpado, soporte de lo dicho se materializa en los criterios que la misma otorga para el efecto, evidenciando en muchos casos sanciones inquisitivas y en otros casos siendo laxos, o llegando a absolver.

\section{Causales del activismo judicial en el proceso disciplinario determinado en la Ley 734 de 2002 (los tipos en blanco y la potestad del funcionario que disciplina de sancionar o absolver)}

El derecho disciplinario es la forma jurídica de regular al servicio público, entendido como la organización política y de servicio, y el comportamiento disciplinario del servidor público, estableciendo los derechos, deberes, obligaciones, mandatos, prohibiciones, inhabilidades e incompatibilidades, así como las sanciones y procedimientos, respecto de quienes ocupan cargos públicos (Sentencia C-030 de 2012); conjunto de normas en virtud de las cuales el Estado asegura la 
obediencia, la disciplina y el comportamiento ético, la moralidad y la eficiencia de los servidores públicos, con miras a asegurar el buen funcionamiento de los diferentes servicios a su cargo.

Su finalidad, es entonces, salvaguardar la obediencia, la disciplina, la rectitud y la eficiencia de los servidores públicos, encontrando allí el fundamento para la responsabilidad disciplinaria, la cual supone la inobservancia de los deberes funcionales de los servidores públicos o de los particulares que ejercen funciones públicas, en los términos previstos en la constitución y la ley.

En este sentido se tiene que, la jurisprudencia constitucional ha sostenido que el derecho administrativo sancionador se encuentra igual que el derecho penal sujeto a los principios constitucionales de legalidad, tipicidad y reserva de ley; principios rectores del debido proceso consagrado en el artículo 29 superior (Sentencia C-818 de 2005), frente a lo cual es importante anotar que tales principios constitucionales consagrados en la Carta Política, adquieren matices de flexibilidad y menor rigurosidad para el caso del derecho sancionador disciplinario (Sentencia C-504 de 2007).

Bajo esta perspectiva, puede indicarse entonces que el derecho al debido proceso en materia administrativa implica el respeto y la garantía de los siguientes principios: i) de legalidad de la falta y de la sanción disciplinaria; (ii) de publicidad; (iii) del derecho de defensa y especialmente el derecho de contradicción y de controversia de la prueba; (iv) del principio de la doble instancia; (v) de la presunción de inocencia; (vi) de imparcialidad; (vii) de non bis in idem; (viii) de cosa juzgada; (ix) de la prohibición de la reformatio in pejes.

Ahora bien, en esta oportunidad se esbozarán las causales del activismo judicial dentro del proceso disciplinario, así:

\section{Los tipos en blanco}

El tópico central será el contenido del principio de legalidad reconocido en varias disposiciones constitucionales que exige que la conducta a sancionar, las sanciones, los criterios para su determinación y los procedimientos previstos para su imposición, deben estar expresa y claramente definidos por la ley con carácter previo a la aplicación de estas medidas; de ahí que la jurisprudencia constitucional haya indicado que este principio comprende una doble garantía: la primera, de orden material y de alcance absoluto, conforme a la cual es necesario que existan preceptos jurídicos anteriores que permitan predecir con suficiente grado de certeza 
aquellas conductas infractoras del correcto funcionamiento de la función pública y las sanciones correspondientes por su realización. La segunda, de carácter formal, hace referencia a la exigencia y existencia de una norma de rango legal, que convalide el ejercicio de los poderes sancionatorios en manos de la administración.

Respecto de las finalidades de este principio, la jurisprudencia constitucional ha señalado que este i) otorga certidumbre normativa sobre la conducta y la sanción a imponer; ii) exige que el texto predeterminado tenga fundamento directamente en la ley, sin que sea posible transferir tal facultad al Gobierno o a las autoridades administrativas, por ser una competencia privativa del legislador (Sentencias C-597 de 1996, C-827 de 2001 y C-796 de 2004); iii) constituye una salvaguarda de la seguridad jurídica de los ciudadanos; iv) protege la libertad individual; v) controla la arbitrariedad judicial y administrativa; vi) asegura la igualdad de todas las personas ante el poder punitivo y sancionador del Estado (Sentencias C-653 de 2001 y C-124 de 2003).

A continuación, se esclarecerá lo propio sobre el principio de tipicidad en materia disciplinaria, el cual exige que la norma creadora de las infracciones y de las sanciones, debe describir clara, expresa e inequívocamente las conductas que pueden ser sancionadas y el contenido material de las infracciones, así como la correlación entre unas y otras. Sobre el particular se tiene que la jurisprudencia de esta corte ha sostenido que el principio de tipicidad se compone de dos aspectos: i) que exista una ley previa que determine la conducta objeto de sanción; ii) la precisión que se emplee en esta para determinar la conducta o hecho objeto de reproche y la sanción que ha de imponerse; aspecto este que se orienta a reducir al máximo la facultad discrecional de la administración en el ejercicio del poder sancionatorio que le es propio (Sentencia C-564 de 2000).

Los conceptos anotados, implican que son varios los aspectos normativos que deben ser regulados de manera clara y expresa en la norma sancionatoria: i) el grado de culpabilidad del agente (si actuó con dolo o culpa); ii) la gravedad o levedad de su conducta (si por su naturaleza debe ser calificada como leve, grave o gravísima); iii) la graduación de la respectiva sanción (mínima, media o máxima según la intensidad del comportamiento). Si el precepto que contiene la conducta jurídicamente reprochable no permite definir tales aspectos, el mismo resulta contrario al principio de tipicidad y proporcionalidad y, por tanto, resulta inconstitucional (Sentencia C-796 de 2004). 
Resulta importante resaltar que aun cuando el principio de tipicidad es exigible en el derecho disciplinario, este se aplica con una mayor flexibilidad y menor rigurosidad en este ámbito por cuanto:

La naturaleza de las conductas reprimidas, los bienes jurídicos involucrados, la teleología de las facultades sancionatorias, los sujetos disciplinables y los efectos jurídicos que se producen frente a la comunidad, hacen que la tipicidad en materia disciplinaria admita -en principio- cierta flexibilidad (Sentencia C-404 de 2001).

La razón fundamental de esta característica del derecho disciplinario se origina en la naturaleza de las normas disciplinarias, toda vez que suelen carecer de completud y autonomía, lo cual hace necesario remitirse a otras preceptivas en donde se encuentren regulados en concreto deberes, funciones, obligaciones o prohibiciones para los diferentes servidores públicos, teniendo en cuenta los cargos y ramas del poder público a los que pertenezcan (Sentencias C-244 de 1996, C-564 de 2000, C-404 de 2001 y C-181 de 2002).

\section{La potestad del funcionario que disciplina de sancionar o absolver}

De esta forma, la Corte Constitucional ha aclarado que en el derecho disciplinario la regla general es que la aplicación de sus normas generales se lleve a cabo a partir de una interpretación sistemática y de una remisión a aquellas otras normas que contienen la prescripción de las funciones, deberes, obligaciones o prohibiciones concretas respecto del cargo o función cuyo ejercicio se le ha encomendado a los servidores públicos, y cuyo incumplimiento genera una falta disciplinaria (Sentencia C-404 de 2001).

Esta forma de definir la tipicidad de la conducta a través de la remisión a normas complementarias, comporta un método conocido por la doctrina y la jurisprudencia como el de las normas o tipos en blanco, que consiste precisamente "en descripciones incompletas de las conductas sancionadas, o en disposiciones que no prevén la sanción correspondiente, pero que en todo caso pueden ser complementadas por otras normas a las cuales remiten las primeras" (Sentencia C-404 de 2001).

En este sentido y de conformidad con Lizarazo (2014), a partir del tipo en blanco que consiste en aquella conducta que no está tipificada en la norma taxativa 
y da lugar a diferentes interpretaciones por cuanto en la misma conducta puede integrarse más de una situación, y se resalta que la remisión que opera por virtud de la comisión de la conducta en blanco constituye simplemente una técnica legislativa de integración del tipo que describe de forma correcta el significado y el alcance del activismo judicial, así las cosas, la norma complementaria se adosa a la conducta básica para integrar el tipo disciplinario, momento a partir del cual este tiene vigencia y poder vinculante completo, lo cual hace que ambas forman una unidad normativa y por tanto llegan a tener plena vigencia.

\section{Los tipos en blanco y la potestad del funcionario que disciplina de sancionar o absolver en los procesos disciplinarios}

Bajo el escenario conceptual descrito, el operador disciplinario no está autorizado para crear faltas administrativas en forma posterior a la realización del comportamiento por parte del destinatario de la ley disciplinaria, pues la Carta Política de Colombia lo prohíbe expresamente, pues de permitirse ello, se afectaría el estado social de derecho y la conformación democrática de la legislación sancionatoria.

Sin embargo, se tiene que los operadores judiciales en materia disciplinaria tienen un amplio margen de movilidad a la hora de calificar la conducta realizada por el sujeto disciplinable, situación que puede resultar benéfica para el disciplinable en algunos casos y en otros casos negativo para los intereses del mismo, ello dependiendo del grado de evaluación y verificación de las características de los tipos disciplinarios que en desarrollo de la técnica jurídica, analice el agente del Estado a la hora de señalar las características que completan y contextualizan la comisión de la falta disciplinaria.

$Y$ en la medida en que se permite la determinación de la falta por tipos abiertos, queda preguntarse entonces si está excluida la ausencia de responsabilidad en materia disciplinaria por atipicidad, cuestionamiento que resulta muy importante, toda vez que el operador jurídico siempre hallará la forma de encontrar la adecuación típica de cualquier conducta, sin existir la posibilidad de librar al servidor encartado por atipicidad.

En este sentido, y atendiendo lo reiterado principalmente por la Corte Constitucional Colombiana (2012): 
La tipicidad en las infracciones disciplinarias se determina por la lectura sistemática de la norma que establece la función, la orden o la prohibición y aquella otra que de manera genérica prescribe que el incumplimiento de tales funciones, órdenes o prohibiciones constituye una infracción disciplinaria (p. 6).

Dichas infracciones pueden ser leves o graves según el funcionario que califique la conducta, pudiéndose en estos casos vulnerar no solo las garantías judiciales sino también el derecho fundamental a un trato igualitario ante la ley.

En este orden de ideas, el operador jurídico con el fin de determinar el tipo disciplinario, se ve en la obligación de acudir a reglamentos internos de trabajo y manuales de funciones, las cuales se pueden definir como normas en sentido laxo inferiores a la ley y a los decretos, extrayéndose de este aspecto que: el agente estatal a través de su amplia función vulnera el principio de legalidad al acudir a dichas normas.

Es posible predicar que en el margen de discrecionalidad en la tipificación de una conducta determinada como tipos en blanco o abiertos, le permite al operador disciplinario complementar la conductas incompletas, o hacer remisión a disposiciones que deben ser perfeccionadas por otros ordenamientos a las cuales se remitan las primeras, sin que per se exista una vulneración a los principios de legalidad en el momento de endilgar un cargo disciplinario, y posterior evaluación al momento de proferir un fallo conforme a la apreciación integral de las pruebas.

\section{Hacia un derecho disciplinario garante del debido proceso}

En retrospectiva, la Ley 200 de 1995 representó un hito en la legislación colombiana, por tratarse del primer intento de reforma a la normatividad disciplinaria para conformar un cuerpo único que comprendiera el régimen de faltas, sanciones y procedimientos como medio de corrección en el ejercicio de la función pública del Estado.

De conformidad con Maya (2014):

El intento resultó acertado, pero en poco tiempo se observaron las deficiencias en puntos tan complejos como un régimen de sanciones que no correspondían a la gravedad de las conductas, la enumeración escasa y taxativa de las faltas gravísimas y la poca claridad en torno al procedimiento aplicable. 
En este sentido, conductas que afectaban de manera verdaderamente grave el correcto funcionamiento de la administración pública no resultaban castigadas o solo podían serlo de modo irrisorio con sanciones que no correspondían a la afectación padecida por la administración. Así, a más de generar impunidad, la gestión disciplinaria no tenía eficacia y poder de disuasión para evitar la comisión de faltas.

Además de la situación descrita, normativamente no se contaba con un régimen especial para los particulares que ejercían funciones públicas, pues se limitaba a mencionar que dichos particulares eran destinatarios de la ley disciplinaria pero no se regulaba lo relacionado con: deberes, prohibiciones y faltas específicas ni las sanciones que deberían imponérseles.

Lo anterior conllevó a una inevitable necesidad de reforma al Código Disciplinario Único que se dio mediante la Ley 734 de 2002, mediante la cual se introdujeron varios cambios que operaron para corregir las fallas mencionadas, entre los que cabe resaltar el desarrollo teórico significativo que condujo a la modernización de esta rama del saber legal, emancipándose del derecho penal y del derecho administrativo.

El debate actual en materia disciplinaria gira en torno al principio de legalidad, anotando que en la tradición colombiana la interpretación autorizada de la Constitución ha promovido los criterios de diferenciación entre conductas delictivas y faltas disciplinarias. Así las cosas, mientras que en las conductas delictivas se ha determinado la exigencia de mayor precisión para cumplir con el supuesto de lex certa debido al importante papel que ha desempeñado en la dogmática penal la categoría de tipicidad como constitutivo esencial del principio de legalidad, en el derecho disciplinario lo propio ha sido establecer normas de reenvío o normas en blanco, pues es frecuente el empleo de conceptos jurídicos indeterminados o las remisiones a otras normas o si se quiere a deberes genéricos.

A este respecto, la lectura de la jurisprudencia constitucional permite reconocer dos fases sobre el particular: con la interpretación de la antigua Constitución se estableció sin mayor diferenciación la aplicación de los principios del derecho penal al derecho disciplinario debido a la necesidad de configurar un marco compartido de garantías básicas para la aplicación de sanciones; marco que se transformó bajo el imperio de la Constitución de 1991, pues se ampliaron las pautas de interpretación siguiendo una visión internacional del derecho humano fundamental al debido proceso que enmarca no solo los aspectos de ritualidad y formalidad del procedimiento, sino verdaderas categorías sustanciales. 
Es de esta forma como el derecho al debido proceso aplicado a actuaciones judiciales y administrativas incorporó en su inventario de aplicación los principios de tipicidad, antijuridicidad y culpabilidad, regla que fue plasmada en la Sentencia C-195 de 1993 y reiterada en sendos pronunciamientos en las Sentencias C-280 de 1996, C-306 de 1996 y C-310 de 1997 proferidas por nuestra Corte Constitucional.

A nivel internacional, se tiene que cualquier actividad sancionatoria dentro de un Estado de derecho se demarca en los principios de legalidad de las infracciones y de las sanciones como parte constitutiva de la garantía de seguridad jurídica para el ciudadano, aunque no se extreman los supuestos de descripción para el caso del derecho disciplinario. Sin embargo, lo importante en este punto es que los destinatarios de la ley disciplinaria conozcan el núcleo de las prohibiciones y su vinculación con el correcto ejercicio de la función pública.

Una descripción de la ley disciplinaria que permita la seguridad jurídica de los destinatarios se complementa con las exigencias trazadas por la Corte Constitucional en la materia, pues a través de sus pronunciamientos ha determinado con toda claridad que la construcción de las faltas disciplinarias no puede sujetarse al arbitrio del intérprete, razón por la cual el principio de reserva legal también se ha considerado como componente de la garantía del debido proceso disciplinario, siendo este el motivo por el que para el alto tribunal constitucional ha resultado perfectamente adecuada la inexequibilidad de la posibilidad de que las prohibiciones se establezcan por vía de reglamento.

De la síntesis de los pronunciamientos de la Corte Constitucional sobre este particular posibilita al menos tres conclusiones: la primera, el legislador es el único autorizado constitucionalmente para determinar las conductas constitutivas de faltas disciplinarias; la segunda, el derecho punitivo y el derecho disciplinario comparten los fundamentos constitucionales que constan como garantías judiciales y principios para que el Estado ejerza su potestad sancionadora; la tercera, las normas disciplinarias tienen por lo general el carácter de normas de reenvío. Sobre este último punto, es oportuno citar el salvamento de voto de la Sentencia C-713 de 2001, en la cual se recogen los argumentos de las decisiones provenientes entre 1994 y 1999 en los que se precisó el alcance del esquema de conformación de tipos en materia disciplinaria indicando que el legislador debe señalar el núcleo de la conducta prohibida, es decir, los elementos mínimos constitutivos de cada falta y la sanción correspondiente, a efectos de que el operador de la norma la 
complemente y la defina, pero, ¿es esto suficiente para dotar de seguridad jurídica a los ciudadanos disciplinables?

No, pues a pesar de los límites que se han marcado no solo a nivel jurisprudencial sino también doctrinal y por supuesto jurisprudencialmente, resulta importante prever situaciones en las cuales la calificación jurídica de las conductas sea inadecuada en abierta vulneración de los principios constitucionales y estándares internacionales, es decir, traspasando los límites trazados por el constituyente y el legislador con fundamento en un amplio margen de discrecionalidad para decidir las conductas que merecen juicio de reprochabilidad jurídica.

Sobre el particular, con el fin de dotar de total transparencia los procesos disciplinarios contra funcionarios públicos o particulares que cumplen funciones públicas, y tutelar no solo los derechos fundamentales de quien es disciplinado sino al operador jurídico, resulta importante introducir en la legislación un listado taxativo de faltas leves, graves y gravísimas que limite las potestades interpretativas de quienes investigan y sancionan en estricta aplicación del principio de legalidad en la misma medida en que se aplica en el derecho penal, pues aunque el derecho disciplinario es más benevolente en las sanciones que impone, pues no se restringe el derecho fundamental a la libertad, sí puede cercenar un proyecto de vida y afectar, en consecuencia, el ámbito personal, social, profesional y familiar del sujeto disciplinado, es decir, la autonomía bajo la cual actúan los operadores jurídicos en la actualidad no se encuentra restringida de manera apropiada por las pautas que imponen la proporcionalidad y la vigencia de los principios de convivencia pacífica y el orden justo.

En concordancia con lo dispuesto anteriormente, es importante la elaboración de líneas jurisprudenciales de la Corte Constitucional acerca de la constitucionalidad de las políticas públicas orientadas a garantizar un derecho constitucional mediante la cual se precisen los requisitos que deben satisfacer las políticas públicas para ser constitucionales, estos requisitos operan como indicadores de constitucionalidad de las políticas públicas (Rodríguez, 2014).

\section{Conclusión}

A continuación se presentarán las conclusiones obtenidas a partir de la pregunta problema de investigación planteada: ¿Cómo opera el activismo judicial en 
el procedimiento disciplinario?, lo cual se logró a través de la aplicación de una investigación cualitativa en la que se utilizó el método dogmático de investigación.

En el cumplimento de los fines propios del estado social y democrático de derecho, cada una de las entidades que conforman la organización administrativa tiene un objetivo institucional dentro de las cuales aparece el servidor público como protagonista, quien a través de sus deberes y funciones permite poner en marcha la ejecución de importantes labores.

En tal sentido, el derecho disciplinario se convierte en una herramienta para realizar el control del cumplimiento del deber funcional establecido para cada servidor público conforme la Constitución Política. Así, el artículo 122 superior proscribe la existencia de empleos públicos que no tengan funciones detalladas; mientras que el artículo 123 señala que los servidores públicos ejercerán las funciones en la forma prevista por la Constitución, la ley y el reglamento. Por lo demás, de similar manera, se dispuso que los particulares que ejerzan funciones públicas tendrán un régimen aplicable cuya reglamentación fue conferida a la ley.

De acuerdo con lo expuesto, en materia disciplinaria la finalidad se limita al encauzamiento de la conducta de los destinatarios de la ley disciplinaria, es decir, que los servidores públicos o los particulares que ejercen funciones públicas procuren disciplina, respetando unas reglas mínimas que deben tenerse en cuenta antes, durante y después de la ocupación de cualquier cargo público. Por lo anterior, el principal instrumento del Estado es de carácter normativo: el agente estatal está obligado a observar la norma subjetiva, esto es, aquella que le orienta a que cumpla sus deberes funcionales, a que no se extralimite en el ejercicio de sus derechos y funciones, a que no incurra en prohibiciones y comportamientos contrarios a la ética y disciplina y a que respete unas reglas mínimas sobre inhabilidades, incompatibilidades y conflictos de intereses.

No obstante, en algunas ocasiones el desvalor de acción desplegado por el servidor público puede llevar aparejado un resultado indeseado, el cual en muchos casos puede ser decisivo para determinar si es razonable o no atribuir la responsabilidad disciplinaria o si esta puede cambiar de forma relevante, aspectos que indudablemente incidirán en la sanción a imponer.

Bajo este escenario, las faltas disciplinarias que requieren para su estructuración de un resultado, hechos en los que el resultado es una condición de agravación de la conducta o cuando por ejemplo el servidor público está obligado a prevenir la ocurrencia de resultados, es necesario analizar no solo la causalidad entre conducta 
y resultado, sino la relevancia típica disciplinaria y si, además, dicho resultado puede ser atribuible a la inobservancia del desvalor de acción desde el punto de vista no solo funcional sino también normativo, aplicando algunos principios de la imputación objetiva del derecho penal.

Ahora bien, a catorce años de expedida la Ley 734 de 2002 y en consonancia con el promovido y arraigado activismo judicial, es menester que, dentro del estado social de derecho a través del legislador, se instituya en el ordenamiento jurídico interno, un listado taxativo de faltas y sanciones que elimine el arbitrio de las decisiones de quienes administran justicia.

Con ello se quiere fortalecer el procedimiento disciplinario a través del principio de legalidad bajo la implementación de una normativa completa en la que se promueva el respeto por la función pública en desarrollo de los principios de igualdad, moralidad y eficacia con el objetivo de cumplir los fines esenciales del Estado, con lo cual Colombia tendrá un modelo de persecución disciplinaria estricto y eficaz en el que prevalezca la seguridad jurídica de quienes desempeñan funciones públicas con plena claridad y congruencia de los principios que rigen el ius punendi en el que no existe ni siquiera una mínima posibilidad de arbitrariedad por parte de los operadores jurídicos ni en la calificación de la falta ni en la imposición de la sanción.

\section{Referencias}

Berdugo, A., et al. (2013, julio-diciembre). La imputación objetiva en derecho disciplinario. Revista Derecho Penal y Criminología, 34(97), 113-157. Bogotá: Universidad Externado de Colombia.

Blanco, C. (2010). La importancia social y política del Parlamento Andino. Revista Via Inveniendi et Iudicandi, 6(1), 221-242. Recuperado de http://revistas.usantotomas.edu. co/index.php/viei/article/view/2941/2813

Cabrillo, F. (2011). Un análisis económico de la administración de justicia: ¿Qué maximizan los jueces? Derecho y economía. Universidad San Martín de Porres.

Corte Constitucional de Colombia. (30 de mayo de 1996). Proceso disciplinario/Proceso penal. Sentencia C-244. [M.P. Carlos Gaviria Díaz].

Corte Constitucional de Colombia. (6 de noviembre de 1996). Principio de unidad de materia: naturaleza. Sentencia C-597. [M.P. Alejandro Martínez Caballero].

Corte Constitucional de Colombia. (27 de mayo de 1999). Banco de la República: autonomía para establecer valor UPAC. Sentencia C-383. [M.P. Alfredo Beltrán Sierra]. 
Corte Constitucional de Colombia. (16 de septiembre de 1999). Inbibición de la Corte Constitucional: carencia actual de objeto. Sentencia C-700. [M.P. José Gregorio Hernández Galindo].

Corte Constitucional de Colombia. (6 de octubre de 1999). Derecho a la vivenda digna. Sentencia C-747. [M.P. Alfredo Beltrán Sierra].

Corte Constitucional de Colombia. (17 de mayo de 2000). Estatuto cambiario. Sentencia C-564. [M.P. Alfredo Beltrán Sierra].

Corte Constitucional de Colombia. (19 de abril de 2001). Libertad de configuración legislativa de norma constitucional. Sentencia C-404. [M.P. Marco Gerardo Monroy Cabra].

Corte Constitucional de Colombia. (20 de junio de 2001). Test de igualdad de falta disciplinaria. Sentencia C-653. [M.P. Manuel José Cepeda Espinosa].

Corte Constitucional de Colombia. (8 de agosto de 2001). Junta directiva del Banco de la República. Sentencia C-827. [M.P. Álvaro Tafur Galvis].

Corte Constitucional de Colombia. (12 de marzo de 2002). Derecho disciplinario. Sentencia C-181. [M.P. Marco Gerardo Monroy Cabra].

Corte Constitucional de Colombia. (4 de febrero de 2003). Bloque de constitucionalidad. Sentencia C-067. [M.P. Marco Gerardo Monroy Cabra].

Corte Constitucional de Colombia. (18 de febrero de 2003). Imposibilidad práctica de encuadrar detallada y exhaustivamente las posibles faltas del servidor público. Sentencia C-124. [M.P. Jaime Araujo Rentería].

Corte Constitucional de Colombia. (24 de agosto de 2004). Población infantil: atención especial y prevalente. Sentencia C-796. [M.P. Rodrigo Escobar Gil].

Corte Constitucional de Colombia. (9 de agosto de 2005). Potestad sancionadora del Estado. Sentencia C-818. [M.P. Rodrigo Escobar Gil].

Corte Constitucional de Colombia. (4 de julio de 2007). Declarar la caducidad del contrato estatal o darlo por terminado sin que se presenten las causales previstas por la ley. Sentencia C-504. [M.P. Clara Inés Vargas Hernández].

Corte Constitucional de Colombia. (7 de abril de 2010). Procedimiento verbal en falta disciplinaria cuando la regla general es el proceso ordinario. Sentencia C-242. [M.P. Mauricio González Cuervo].

Corte Constitucional de Colombia. (1 de febrero de 2012). Código disciplinario único. Sentencia C-030. [M.P. Luis Ernesto Vargas Silva].

Corte Constitucional de Colombia. (16 de julio de 2014). Código disciplinario único: clasificación y limite de las sanciones. Sentencia C- 500. [M.P. Mauricio González Cuervo]. 
Corte Interamericana de Derechos Humanos. (2 de febrero de 2001). Caso Baena Ricardo y otros vs. Panamá. Sentencia de serie C n.o 72. Recuperado de http://www.corteidh. or.cr/docs/casos/articulos/Seriec_72_esp.pdf

Corte Interamericana de Derechos Humanos. (1 de septiembre de 2011). Caso de Leopoldo López vs. Venezuela. Sentencia de fondo, reparaciones y costas. Sentencia de serie C n.o 233. Recuperado de http://corteidh.or.cr/docs/casos/articulos/seriec_233_esp.pdf

Forero, R. (2016, enero-junio). La protección constitucional de las víctimas en Colombia, desde la óptica del derecho disciplinario, con énfasis en la garantía consagrada en la Ley 1448 de 2011. Revista Verba Iuris, (35), 85-95.

Green, C. (2009). An intellectual history of judicial activism. Emory Law Journal, 58(5).

Lizarazo, L. (2014). Los tipos en blanco del régimen disciplinario de las fuerzas militares - Ley 836 de 2003. Bogotá: repositorio de la Universidad Militar Nueva Granada Recuperado de http://repository.unimilitar.edu.co/bitstream/10654/12578/1/tipos\%20 en\%20blanco11.pdf

Maya, E. (2016). Estado actual del derecho disciplinario en Colombia. Recuperado de http:// www.colegiodederechodisciplinario.com/jmv.html

Ramírez, M. L., y Álvarez, P. (2015). El principio non bis in idem en el derecho disciplinario del abogado, en Colombia. Revista Ius et Praxis, 21(1), 345-376.

Rodríguez, A. (2014). Indicadores de constitucionalidad de las políticas públicas: enfoque de gestión de derechos. Revista Via Inveniendi et Iudicandi, 9(2), 135-175. Recuperado de http://revistas.usantotomas.edu.co/index.php/viei/article/view/2438 